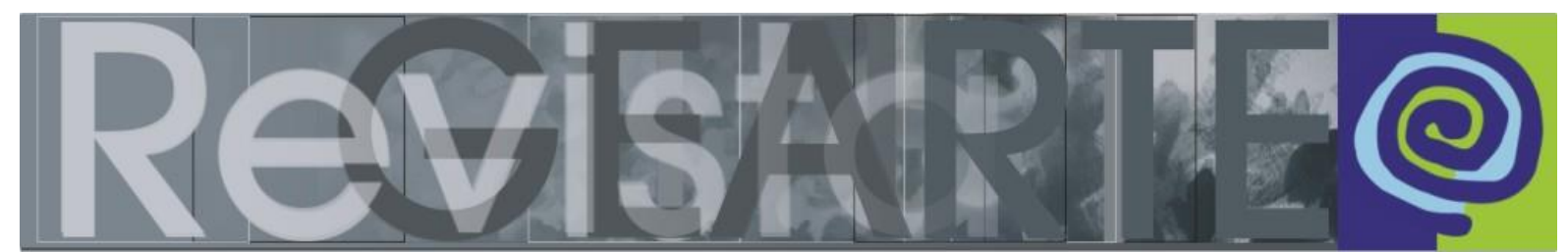

ISSN 2357-9854 | e-ISSN 2596-3198 (online)

\title{
O ensino de história da indumentária brasileira nas aulas de artes visuais: inserções possíveis
}

\author{
Elton Luís Oliveira Edvik \\ (Universidade Federal do Rio de Janeiro — UFRJ, Rio de Janeiro, Brasil)
}

\begin{abstract}
RESUMO - $O$ ensino de história da indumentária brasileira nas aulas de artes visuais: inserções possíveis - Este estudo discute as possibilidades de inclusão do ensino de história da indumentária brasileira nas aulas de artes visuais para turmas do Ensino Médio e dos anos finais do Ensino Fundamental. Para tanto, foi realizado levantamento de modo a oferecer um breve histórico dos estudos de indumentária e de moda, especialmente no Brasil. A partir deste panorama, foram apontadas possibilidades de pesquisa no campo da história da arte tomando a representação da indumentária como chave de leitura das imagens. As fontes visuais elencadas para sustentar a discussão foram as obras de artistas viajantes em visita ao Rio de Janeiro no início do século XIX. PALAVRAS-CHAVE

Indumentária brasileira. História da arte. Artes Visuais. Ensino.
\end{abstract}

\begin{abstract}
Teaching Brazilian History in Visual Arts classes: possible insertions - This study discusses the possibilities of including teaching Brazilian History in Visual Arts classes for high school classes and the final years of elementary school. To this end, a survey was carried out in order to offer a brief history of dress and fashion studies, especially in Brazil. Based on this panorama, research possibilities were identified in the field of Art History, taking the representation of clothing as a key to reading images. The visual sources listed to support the discussion were the works of traveling artists visiting Rio de Janeiro in the early 19th century.
\end{abstract}

KEYWORDS

Brazilian clothing. Art history. Visual arts. Teaching.

RESUMEN - Enseñanza de la Historia de la Vestimenta Brasileña en las clases de Artes Visuales: posibles inserciones - El presente estudio analiza las posibilidades de incluir la enseñanza de la Historia de la Ropa Brasileña en las clases de Artes Visuales para las clases de secundaria y los últimos años de la escuela primaria. Con este fin, se realizó una encuesta para ofrecer una breve historia de los estudios de vestimenta y moda, especialmente en Brasil. En base a este panorama, se identificaron posibilidades de investigación en el campo de la Historia del Arte, tomando la representación de la ropa como clave para leer imágenes. Las fuentes visuales enumeradas para apoyar la discusión fueron las obras de artistas itinerantes que visitaron Río de Janeiro a principios del siglo XIX.

PALABRAS CLAVE

Vestimenta brasileña. Historia del Arte. Artes Visuales. Enseñanza. 


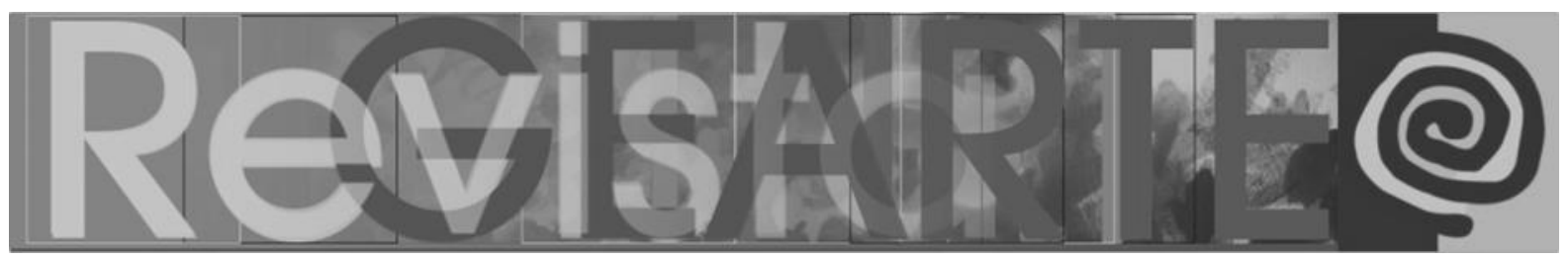

\title{
Introdução
}

Durante a primeira metade do século XIX, muitos viajantes estrangeiros transitaram pelo Brasil, sobretudo pelo Rio de Janeiro. A cidade passara de capital da Colônia Portuguesa na América à sede do novo Império Português. Esse novo status unido à instalação de uma sociedade de corte impulsionaram o processo civilizatório na cidade. Segundo o historiador Boris Fausto:

\begin{abstract}
O acesso aos livros e uma relativa circulação de ideias foram marcas distintivas do período. Em setembro de 1808, veio a público o primeiro jornal editado na Colônia; abriram-se também teatros, bibliotecas, academias literárias e científicas para atender aos requisitos da Corte e de uma população urbana em rápida expansão. (FAUSTO, 2010, p. 129)
\end{abstract}

Estima-se que uma elite contendo entre dez e quinze mil pessoas acompanhou o príncipe regente D. João. Em meio a tantas transformações, os artistas viajantes aproveitaram para retratar os hábitos dos habitantes do Rio de Janeiro. Muitos destes artistas, notadamente europeus, eram integrantes de expedições científicas e buscavam retratar as excentricidades do Novo Mundo.

Neste contexto, a representação da indumentária carioca mostra-se como um importante meio de análise social e oferece diversas possibilidades de reflexão sobre a História da Arte no Brasil durante a primeira metade do século XIX. Assim, a partir da indumentária retratada, é possível perceber a adoção, pelos brasileiros, aos padrões estéticos de procedência europeia. É preciso, também, pensar essa representação e os interesses dos artistas. Deve-se ter em mente que os viajantes estrangeiros já traziam imagens preconcebidas da realidade que iriam encontrar. Com seu olhar de homem branco colonizador, esse observador por vezes registrou e divulgou a imagem do outro de maneira estereotipada. Segundo Peter Burke, os estereótipos muitas vezes são formados pela oposição da autoimagem do espectador. $\mathrm{O}$ autor acredita que:

[...] os estereótipos mais grosseiros estão baseados na simples pressuposição de que "nós" somos humanos ou civilizados, ao passo que "eles" são pouco diferentes de animais como cães e porcos, aos quais eles são frequentemente comparados. (BURKE, 2004, p. 157) 


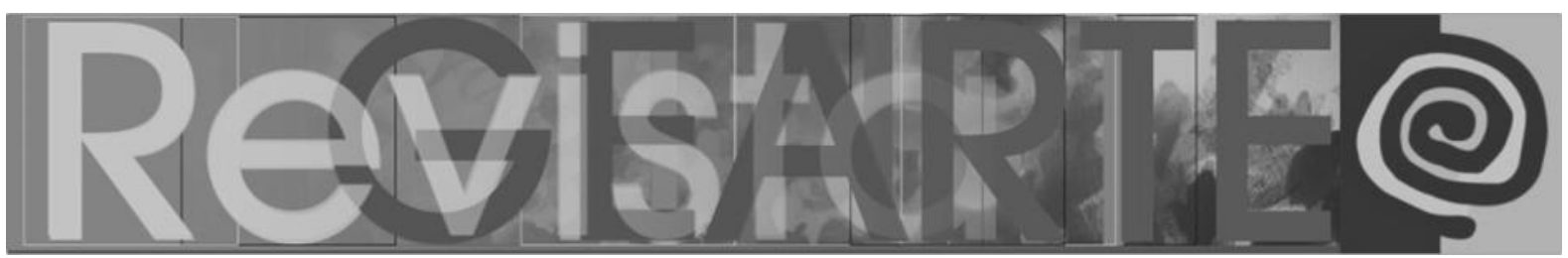

Deste modo, entende-se o processo de estereotipagem como um processo de desumanização, uma vez que "eles" são transformados em exóticos e distanciados do "eu".

Diante de tais apontamentos, pode-se pensar na seguinte questão: de que modo os professores de Artes Visuais (Ensino Fundamental II e Ensino Médio) podem discutir a arte produzida no Brasil durante a primeira metade do século XIX a partir da representação da indumentária?

\section{Breve historiografia dos estudos de indumentária e de moda}

O Conselho Internacional de Museus e Coleções de Indumentária (International Council of Museums and Collections of Costume - ICOM) propõe três instâncias classificatórias de trajes, ornamentos, acessórios e demais objetos associados à vida pública e privada nas sociedades modernas e contemporâneas. São elas: esfera eclesiástica, civil e militar. Seguindo os passos de Maria Cristina Volpi, entendemos a indumentária como "o sistema vestimentar formal e normativo de uma sociedade, formado por elementos que compõem a aparência vestida" (VOLPI, 2016, p. 72). A indumentária civil, portanto, revela o aspecto social do vestuário e tem o poder de incorporar os valores do imaginário coletivo e as normas da realidade vivida. A moda, por sua vez, é um conjunto de valores, faz parte da indumentária, mas existem roupas que não se enquadram na lógica da moda, como os uniformes militares ou os hábitos dos padres.

Em Sistema da moda, Roland Barthes aponta a existência de três tipos de vestuário: o vestuário-imagem, o vestuário-escrito e o vestuário real. O vestuárioimagem é aquele cuja representação visual é bidimensional e o vestuário-escrito é aquele transformado em linguagem escrita. Já o vestuário-real, como o próprio Barthes destacou, possui uma estrutura que "só pode ser tecnológica; as unidades dessa estrutura só podem ser os vestígios diversos dos atos de fabricação, seus fins realizados, materializados" (BARTHES, 2009, p. 22). Desse modo, Barthes 


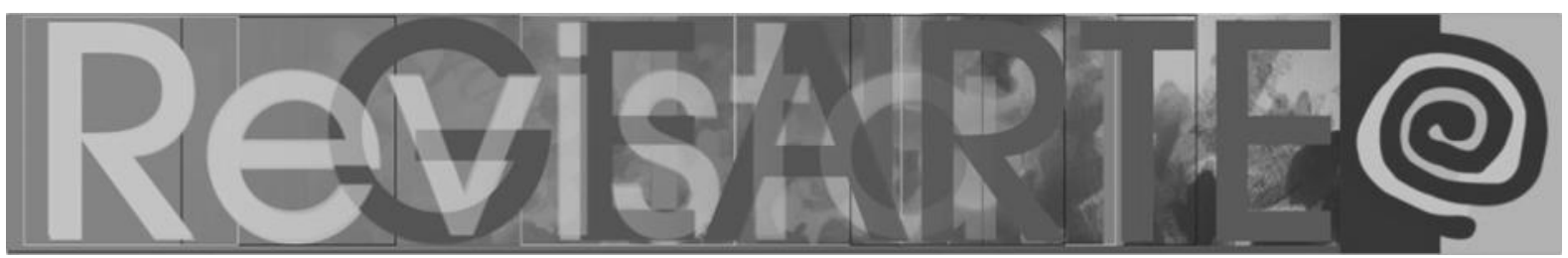

chama a atenção para as significações e valores imputados pela mídia impressa aos objetos, no caso, o vestuário.

Tido como um objeto de estudo frívolo e supérfluo (SILVA, 2019), a moda foi negligenciada por muitos anos. Ao longo do século XIX e início do XX, ainda que timidamente, ela tornou-se objeto de estudo das ciências humanas e em especial da Sociologia, História e Psicologia. A historiografia da indumentária e da moda ocidental foi construída apoiando-se numa lógica eurocêntrica e inserida na tradição dos estudos históricos sobre o vestuário que nasceram da prática museológica e arquivística. Neste contexto, inserem-se as obras basilares de François Boucher, Carl Köhler e James Laver. Transitando entre a teoria e a prática, a figurinista, modelista e museóloga Janet Arnold debruçou-se no estudo da construção das roupas dos ingleses dos séculos XVI e XVII e suas modelagens continuam sendo estudadas e reproduzidas. Destacamos, ainda, alguns teóricos modernos e contemporâneos que estudaram, direta ou indiretamente, a moda e a indumentária e cujas pesquisas não podem ser negligenciadas. São eles: Thorstein Veblen, Gabriel Tarde, Philippe Perrot, Daniel Roche, Georg Simmel, Pierre Bourdieu, Roland Barthes, Elizabeth Wilson, Umberto Eco, Gilles Lipovetsky, Yuniya Kawamura, Lou Taylor, Caroline Evans e Diana Crane'1.

No caso do Brasil, a falta de uma cultura de conservação das peças de indumentária histórica faz com que o pesquisador muitas vezes não disponha do "vestuário real". Ainda assim, pensando na indumentária brasileira numa perspectiva histórico-sociológica, importantes pesquisas foram e vêm sendo desenvolvidas, como é o caso do trabalho pioneiro de Gilda de Mello e Souza²

Não podemos deixar de evidenciar o trabalho de Sophia Jobim, primeira professora de Indumentária Histórica da Escola Nacional de Belas Artes, hoje incorporada à Universidade Federal do Rio de Janeiro. Jobim criticava a divisão das artes em artes maiores e menores, e defendia que a História do Vestuário fazia parte do campo da etnografia, no bojo das Ciências Sociais (OLIVEIRA, 2016). 


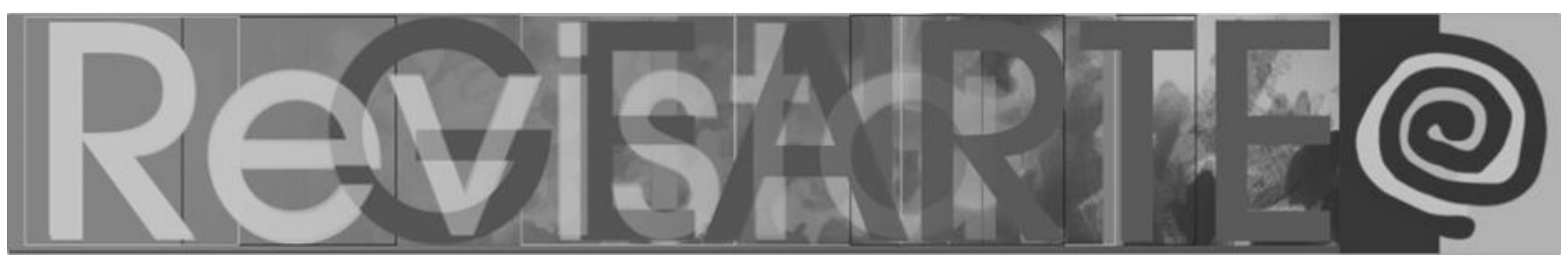

Destacamos ainda os estudos feitos por Maria Cristina Volpi, Maria do Carmo Teixeira Rainho, Maria Claudia Bonadio, Maria Lucia Bueno, Rita Andrade, Mara Rúbia Sant'Anna, Gilda Chataignier, entre outros ${ }^{3}$. Sobre a questão da conservação de têxteis, Fausto Viana lança mão dos trajes de cena para discutir a necessidade de preservar esses artefatos e as formas de fazê-lo 4 . Não podemos deixar de citar alguns autores que, ainda que não tenham a moda como principal objeto de estudo, discutem em suas obras sobre a aparência vestida dos brasileiros e acabam por contribuir decisivamente para as pesquisas, em especial as que tratam do século XIX. São eles: Gilberto Freyre (sociologia), Maria Beatriz Nizza da Silva (história), Joaquim Manoel de Macedo, José de Alencar e Machado de Assis (literatura) e Luís Edmundo e João Affonso (crônica).

As fontes de pesquisa utilizadas pelos autores brasileiros citados até aqui, especialmente quando não há o "vestuário-real" preservado, são as mais variadas. Dentre as principais, destacamos os famosos manuais de etiqueta publicados no Brasil e em Portugal, as revistas e os jornais femininos, as várias teses sobre saúde e higiene apresentadas à Faculdade de Medicina do Rio de Janeiro, os romances, memórias, enciclopédias, inventários, testamentos e recibos de compra e venda.

Philippe Perrot enfatiza a necessidade de aprofundar a dimensão verdadeiramente social do vestuário. Para o autor, a história das vestimentas geralmente falha por se limitar à descrição literal e ao julgamento estético, "evitando ainda abordar o terreno dos gestos, da anatomia, da sexualidade, da higiene, da economia, do signo, dos ritos, da religião, da moral ou do direito" (PERROT, 2002 apud RAINHO, 2002, p. 12), terrenos esses que podem ser explorados a partir da análise de nossos comportamentos vestimentários.

Os primeiros estudos históricos sobre o vestuário tinham como fonte principal obras de arte como pinturas, esculturas, gravuras e medalhas (NACIF, 2012). Estas obras eram estudadas sem relação com outros referenciais teóricos. No contexto dos séculos XVII e XVIII, estes estudos faziam parte de um ramo menor da História da Arte. Ao refletir sobre o lugar das roupas no campo da História 


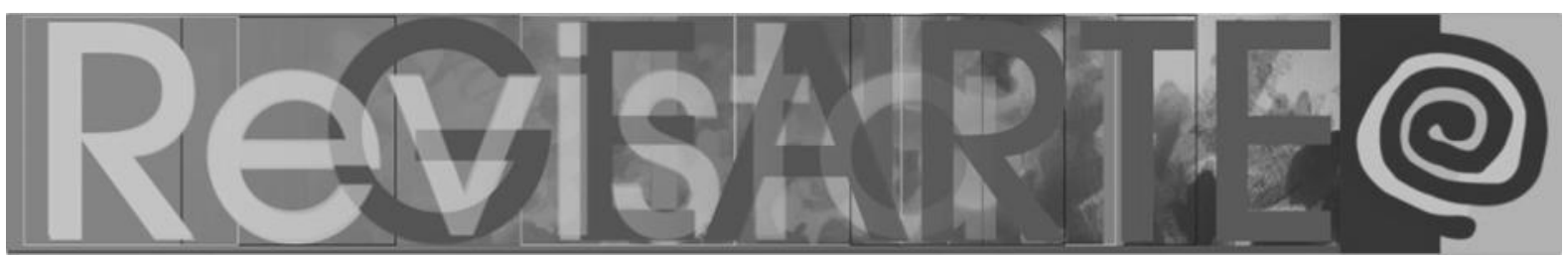

da Arte, Nacif revela que o tema continua sendo negligenciado apesar de oferecer diversas possibilidades de novos estudos.

Ao abordar a questão estética das formas, matérias e estilos na construção da aparência, da relação das roupas com os espaços de vivência, da relação entre criação artística e o design, temos os pontos de partida para novas reflexões e um dos principais desafios para os estudos do vestuário e da moda. (NACIF, 2012, p. 1136)

Assim, somos instigados a estudar mais a fundo essas manifestações complexas (o vestuário e a moda) do ponto de vista da História da Arte, de modo a construir um caminho mais acolhedor para futuros pesquisadores.

\section{A representação da indumentária brasileira no início dos oitocentos: discussões possíveis nos anos finais do Ensino Fundamental e no Ensino Médio}

A discussão sobre as fontes de estudo da indumentária e da moda numa perspectiva histórica continua a apresentar alguns problemas e negligências. Seja como for, sabemos que as imagens são fontes que possibilitam análises a partir de diversas perspectivas. Assim, devemos despertar nosso olhar crítico sem desmerecer a imagem como fonte de estudo da História. Paulo Knauss (2006, p. 100) defende que:

[...] desprezar as imagens como fontes da História pode conduzir a deixar de lado não apenas um registro abundante, e mais antigo do que a escrita, como pode significar também não reconhecer as várias dimensões da experiência social e a multiplicidade dos grupos sociais e seus modos de vida. O estudo das imagens serve, assim, para estabelecer um contraponto a uma teoria social que reduz o processo histórico à ação de um sujeito social exclusivo e define a dinâmica social por uma direção única.

Deste modo, entendemos que uma análise apurada da representação da indumentária possibilita uma série de importantes discussões acerca da sociedade em questão. Em outras palavras, as imagens revelam os hábitos cotidianos e nos aproximam daquela realidade tão distante temporalmente. 


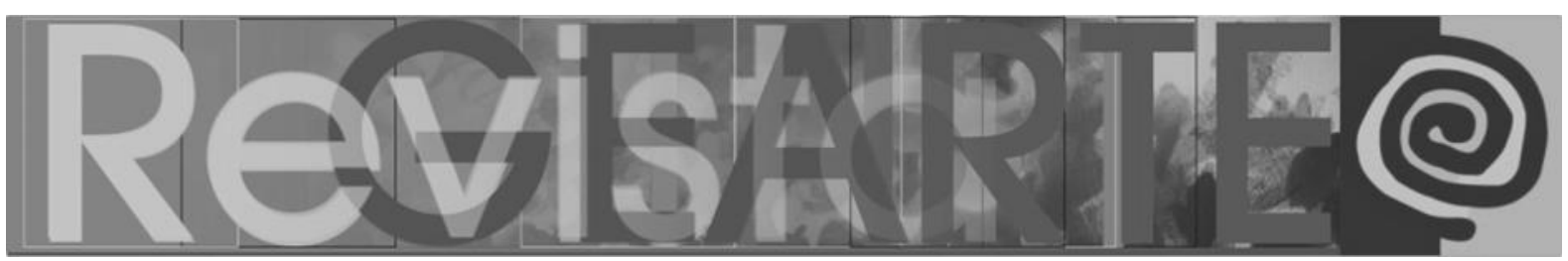

Não é de hoje que os educadores investem no diálogo entre o ensino de Artes Visuais e os estudos de indumentária e de moda. No Brasil, tal iniciativa iniciou-se com o desenho de peças de vestuário na Escolinha de Arte de São Paulo. Segundo Ana Mae Barbosa,

\begin{abstract}
Nos inícios de 1970, a Escolinha de Arte de São Paulo não só trabalhou com projetos, como ainda é a moda hoje, mas também ousou introduzir crianças e adolescentes à fotografia, à análise de televisão, à análise visual de objetos de design em lojas especializadas e ao desenho de observação da moda em roupa. (BARBOSA, 2014, p. 9)
\end{abstract}

Na época, as propostas educacionais da instituição eram pensadas, sobretudo, para o público infantil. Já no contexto atual, pode-se pensar numa educação visual que lança mão da história da arte e do design para formar, em todo o ensino básico, um olhar capaz de refletir sobre questões culturais, sociais e estéticas.

Faz-se necessário, assim, discutir o caráter artístico da moda. Há teóricos que insistem em classificá-la como uma arte utilitária (ou artes menores), excluindo-a das tradicionais Belas Artes. Afastando essa necessidade de categorização, Gilda de Mello e Souza defende que

[...] não é possível estudar uma arte, tão comprometida pelas injunções sociais como é a moda, focalizando-a apenas nos seus elementos estéticos. Para que a possamos compreender em toda a riqueza, devemos inseri-la no seu momento e no seu tempo, tentando descobrir as ligações ocultas que mantém com a sociedade. Este fenômeno social, não há dúvida, está jogando a todo instante com os princípios artísticos, que reorganiza num novo todo cada vez que o estilo varia. (SOUZA, 1987, p. 51)

Souza (1987) havia percebido que uma análise puramente estética fortalece a ideia de que a moda é um objeto de estudo trivial e fútil. É preciso investir numa reflexão que leve em consideração uma série de questões caras à história da vida privada, tais como: corpo, higiene, clima etc.

A abertura dos portos às nações amigas em 1808 permitiu a entrada de artigos importados, principalmente de origem inglesa. Esse período foi marcado por grandes mudanças políticas, econômicas e sociais e as modas acompanharam-nas (RASPANTI, 2013). O acesso aos itens de luxo ligados à 


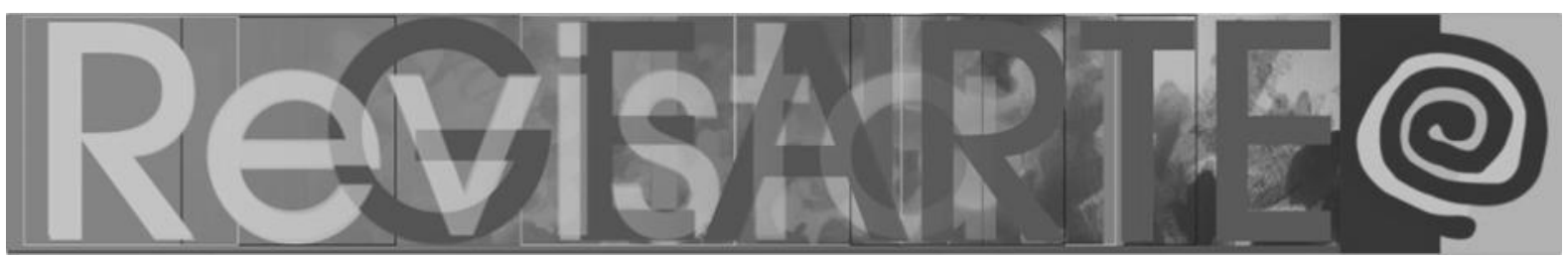

indumentária e à beleza tornou-se mais fácil, especialmente no Rio de Janeiro. A Rua do Ouvidor foi ocupada por lojas e maisons que privilegiavam a moda feminina ${ }^{5}$. Roupas, tecidos, perucas, luvas, lenços, sapatos, águas de colônia, cosméticos, leques, bijuterias, meias, espartilhos e chapéus, entre outros artigos até então inimagináveis às brasileiras passaram a ser comercializados ${ }^{6}$.

A venda de artigos para homens era dominada pelos ingleses e se concentrou nas ruas Direita e da Alfândega. Os cariocas podiam adquirir uma infinidade de tecidos finos, meias e lenços de seda, luvas, casacas, chapéus, coletes, gravatas, jaquetas, pistolas e artigos para montaria. O sociólogo brasileiro Gilberto Freyre afirma que, a partir da chegada de D. João VI ao Brasil, o vestuário masculino foi adquirindo um aspecto quase de luto fechado. "A sobrecasaca preta, as botinas pretas, as cartolas pretas, as carruagens pretas enegreceram nossa vida quase de repente" (FREYRE, 2004, p. 433). Segundo Freyre, o preto e o cinzento eram considerados cores civilizadas, urbanas, burguesas, em oposição às rústicas, às orientais, às africanas e às plebeias.

Esse processo pelo qual a paisagem brasileira foi se acinzentando é chamado, por Freyre, de europeização ou de reeuropeização do Brasil. O escritor afirma que o termo "reeuropeização" é mais cabível já que esse processo se deu por conta da renovação do contato com a Europa. Renovação essa iniciada em 1808 a partir da chegada da corte portuguesa ao Brasil e da abertura dos portos às nações amigas. Mas, é a partir da Independência que se tornou evidente a reeuropeização das modas. Freyre (2004) revela o impacto desse processo na paisagem brasileira:

\footnotetext{
A reeuropeização do Brasil começou fazendo empalidecer em nossa vida o elemento asiático, o africano ou o indígena, cujo vistoso de cor se torna evidente na paisagem, no trajo e nos usos dos homens. Na cor das casas. [...] $\mathrm{Na}$ cor dos xales das mulheres e dos ponchos dos homens; dos vestidos e das roupas; dos chinelos de trançado feitos em casa; das fitas que os homens usavam nos chapéus; dos coletes que ostentavam, opulentos de ramagens; dos chambres de chita que vestiam em casa, por cima do corpo só de ceroulas; das flores que as moças espetavam no cabelo. (FREYRE, 2004, p. 432)
} 


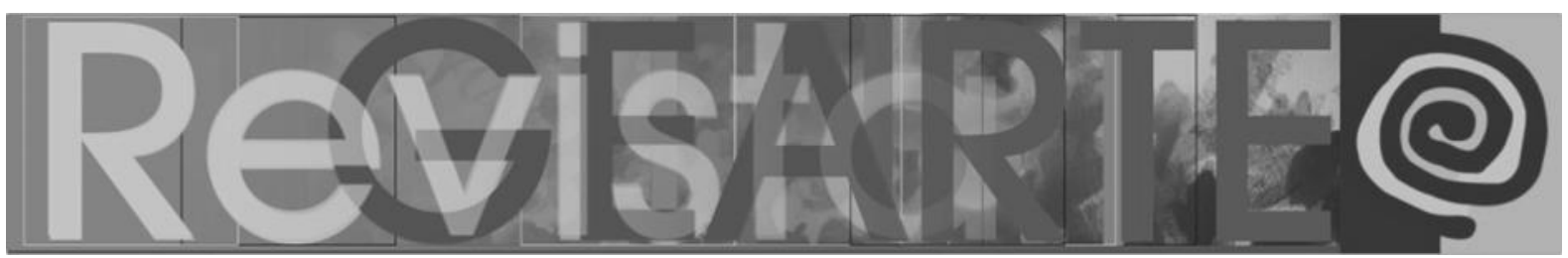

O autor defende que a Europa impôs ao Brasil o preto, o pardo, o cinzento e o azul escuro de sua civilização carbonífera. As cores que, segundo Freyre, davam um tom oriental à vida dos brasileiros foram empalidecendo e tornaram-se excepcionais. Passaram a ser usadas nos dias de feriado, de festa, de procissão, de carnaval e de parada militar (FREYRE, 2004).

Maria do Carmo Teixeira Rainho nota que a europeização dos costumes após a chegada da Corte foi tida como uma espécie de "processo civilizatório". Dentro destes costumes, estão os cuidados com a higiene, a correção dos modos, as boas maneiras à mesa e, claro, a adequação e distinção no vestir. Assim sendo, a adoção das modas estrangeiras tornou-se uma exigência imposta à "boa sociedade". A historiadora defende que, "no decorrer do século XIX, a moda assim como o polimento dos costumes e o refinamento do gosto vão ser importantes na definição dos membros daquela camada" (RAINHO, 2002, p. 44). Toda essa transformação foi feita tendo em vista o igualar-se, na aparência, aos europeus. Dessa maneira, os civis utilizaram a moda, especialmente os padrões indumentários ingleses e franceses ${ }^{7}$, para marcar suas posições sociais.

Diante das proposições acima defendidas, deve-se ter em mente que a reeuropeização e o consequente acinzentamento da paisagem brasileira foram processos lentos, que se consolidaram a partir do reinado de D. Pedro II. Desse modo, presume-se que os pintores Jean-Baptiste Debret (1768-1848) e Johann Moritz Rugendas (1802-1858), em suas respectivas "viagens pitorescas" ao Brasil, pouco retrataram os efeitos desses processos na indumentária brasileira. 


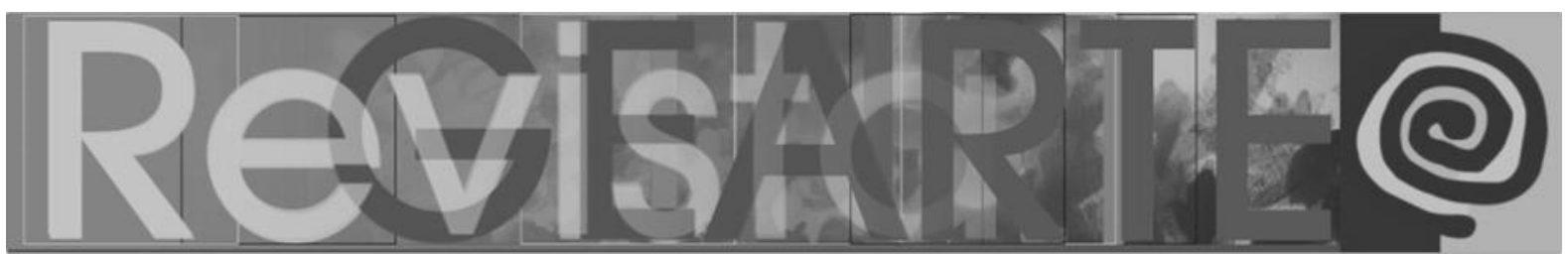

Figura 1 - Jean-Baptiste Debret, Partida da rainha para Portugal, 1821. Aquarela

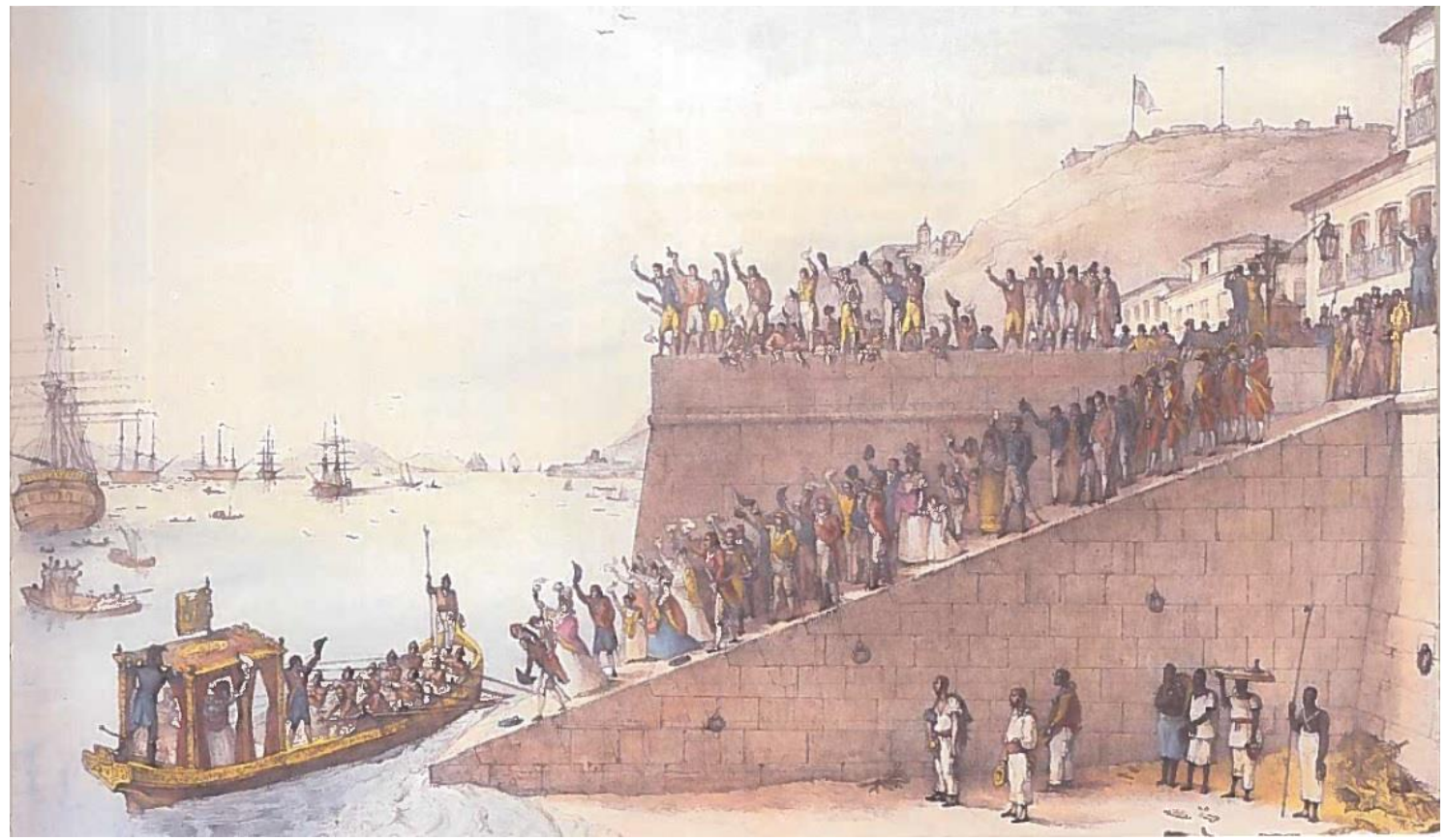

Fonte: Debret (2001).

A prancha acima trata, segundo Debret, do momento do embarque da rainha Carlota Joaquina, de suas filhas e de seu camareiro-mor. A corte portuguesa estava deixando o Rio de Janeiro e seguindo de volta para Lisboa naquele dia 21 de abril de 1821. O momento escolhido para a pintura é aquele em que a rainha responde com o lenço às saudações de seus súditos. Apesar de identificarmos uma certa unidade nas silhuetas masculinas e femininas, o que nos permite distingui-las, a imagem pouco se presta para uma análise do vestuário. Ainda assim, esse olhar panorâmico do pintor nos ajuda a refletir sobre a questão do acinzentamento da paisagem.

Até a chegada da corte portuguesa, em 1808, as influências orientais eram facilmente identificadas no Rio de Janeiro. A partir de então, inicia-se esse processo de acinzentamento da paisagem chamado de "reeuropeização" por Freyre, "desorientalização" por Rainho e de "desassombramento" pelo padre Luís Gonçalves dos Santos. Contudo, é a partir de 1850 que essas novas formas de vestir tornam-se identificáveis. A pintura acima sugere que esse processo ainda não tinha surtido efeito no início da terceira década do século XIX. Vemos um Rio 


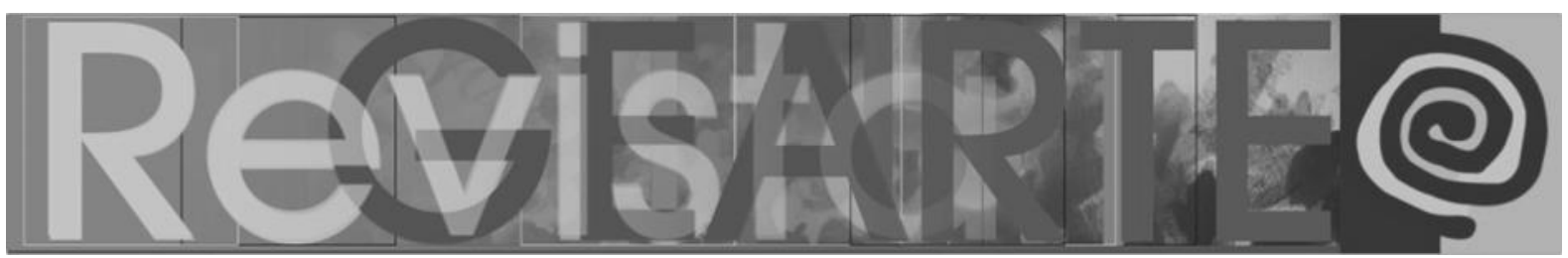

de Janeiro solar não só pela paisagem natural, mas pela alegria transmitida pelas vistosas cores do vestuário de seus habitantes ${ }^{8}$. É sabido que a essa altura os comerciantes ingleses e franceses já dominavam a cidade. Todavia, a importação de produtos do oriente não cessou. O comerciante inglês John Luccock observou, por volta de 1818, a chegada de navios oriundos do oriente:

Os carregamentos de retorno desses navios constam principalmente de tecidos de algodão da Índia, dos quais grande quantidade é reexportada para Portugal, para as colônias da Costa d'África e para todos os portos da América que ficam para o sul da linha do Equador. [...] Os carregamentos vindos da China consistem principalmente de chá, tecidos de nanquim, chumbo, cobre, estanho, sedas e alguns gêneros variados. (LUCCOCK, 1975, p. 394)

Tal observação permite-nos entender os motivos pelos quais esse processo de "acinzentamento" foi lentamente assimilado. O fato é que, em artigos de moda, o Brasil sempre foi essencialmente importador (NASCIMENTO, 2014, p. 98) .

A inglesa Jemima Kindersley foi a primeira mulher estrangeira a publicar uma descrição do Brasil. Ela desembarcou na Bahia de Todos os Santos em agosto de 1764, ali permanecendo por cerca de um mês. Nessa ligeira visita, Kindersley registrou suas impressões sobre as roupas de "uma senhora de boa sociedade" em São Salvador:

As suas vestimentas são pensadas para o clima quente. A mulher mais bem-arrumada que pude ver por aqui portava uma saia de chita, uma florida e folgada camisa de musselina, com profundos folhos e com uma gola do mesmo tecido, pregada por cima. O espartilho ou corpete não fazia parte de seu traje, mas somente uma tira de veludo vermelho enrolada diversas vezes na cintura. O seu cabelo estava para trás, fixado com vários pentes; havia brincos nas suas orelhas e uma espécie de garça, ou melhor, uma massa de ouro maciço, cravejada de diamantes, ornando a sua cabeça; no pescoço, trazia várias correntes finas de ouro e, nos pulsos, uns braceletes de grande espessura, do mesmo material em cada um deles havia ouro suficiente para dois. Um par de chinelos, do mesmo tecido da faixa, completava a vestimenta. (KINDERSLEY, 1764 apud FRANÇA, 2012, p. 271)

O relato de Jemima Kindersley em nada se assemelha ao de Debret. Sabemos que eles estavam se referindo a habitantes de cidades distintas, mas por que a diferença no vestuário seria tão discrepante? Trata-se das maiores cidades brasileiras 


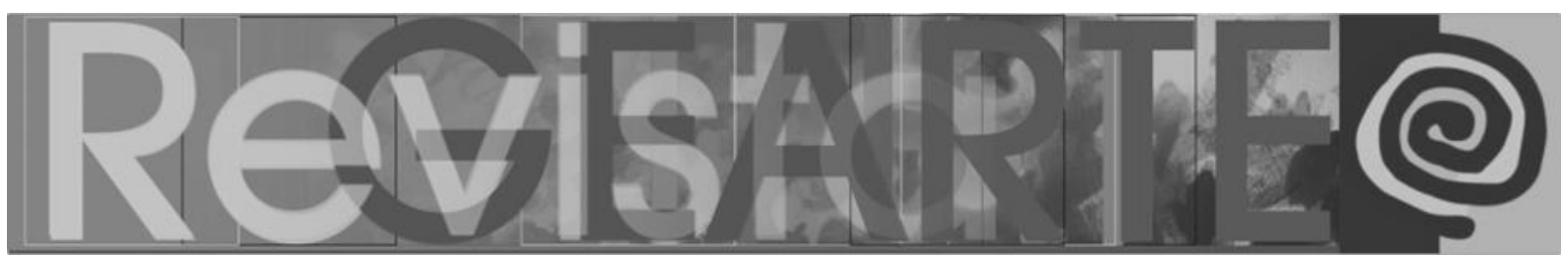

naquele momento. Quando Kindersley esteve em São Salvador, em 1764, a cidade acabara de deixar de ser a capital do Brasi ${ }^{10}$. Mas por que as mulheres se vestiam de maneira não simplória? Podemos levantar hipóteses. A mulher pintada por Debret seria uma portuguesa, ou descendente direta, que trouxe as roupas e os modos de vestir de Lisboa em 1808. Já a simplicidade da baiana descrita por Kindersley se justifica no pouco contato dos brasileiros com produtos estrangeiros àquela altura. Os portos ainda estavam fechados às nações amigas. Sem contar que os costumes da "boa sociedade" só seriam alterados profundamente a partir da chegada da corte portuguesa, em 1808 (RAINHO, 2002, p. 55).

João Affonso do Nascimento (2014) descreveu o vestuário feminino em voga nos primeiros anos do Brasil oitocentista de maneira parecida com o também historiador Luís Edmundo. Tem-se a impressão, em alguns momentos, de que Nascimento não diferencia o vestuário brasileiro do francês, ou de que seu olhar se mantém fixo nas modas de Paris, como na descrição a seguir:

[...] a mulher conservava o vestido talhado à maneira grega, que as faceiras da República tanto imitaram, até chegarem ao exagero da merveilleuse, e agora, menos ridículo, continuava, entretanto, a ser a estreita túnica, bem decotada, atada embaixo dos braços por um cinto bordado de pedrarias, de mangas tufadas no alto e descendo depois ao braço até cobrir a mão; penteado à grega, enrolando-se o cabelo, geralmente num pito, circulado por uma fita, um fio de pérolas ou um diadema. (NASCIMENTO, 2014, p. 96)

É preciso reiterar que devemos localizar o discurso de cada teórico e de cada viajante estrangeiro. E é com essa consciência que devemos discutir as representações da indumentária presente nas pinturas e nos relatos de estrangeiros. Acerca da indumentária feminina, Rugendas fez o seguinte relato:

\footnotetext{
$\mathrm{Na}$ capital, a indumentária das mulheres varia de acordo com a moda. Entretanto, elas não gostam de mudar nem de tecido nem de cor, sendo os vestidos quase sempre de tafetá preto. O preto é também a cor da mantilha, sem a qual nenhuma mulher sai, em geral; elas usam flores frescas nos cabelos e na cintura e um lenço leve ou guirlanda, cujas cores variadas suavizam o que o vestido tem de demasiado sombrio. (RUGENDAS, 1998, p. 131)
} 


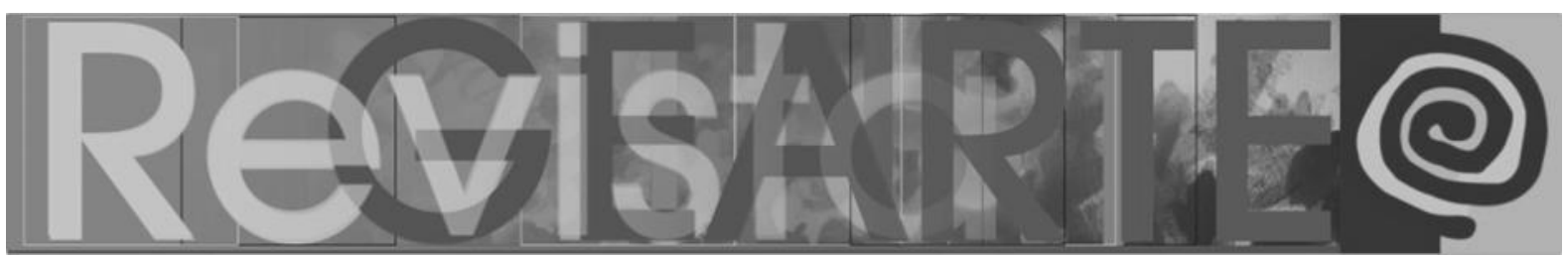

Esse enlutamento da indumentária feminina, citado por Rugendas e por M. de la Flotte, torna-se uma contradição quando são observadas as aquarelas daquele de plano geral, como é o caso de Vista tomada em frente da Igreja de São Bento no Rio de Janeiro, aquarela que nos revela a incoerência referente ao excessivo uso de roupas pretas pelas mulheres da capital. Apesar disso, o prussiano Leithold, que esteve no Rio de Janeiro em 1819, fez o seguinte relato: "[...] durante a saída dominical para a missa, as mulheres vestiam-se de preto, geralmente de seda, com meias de seda branca, sapatos da mesma cor e sobre a cabeça um véu preto de fino crepe que cobre a metade do corpo"11 (SILVA, 1993, p. 231).

\section{Considerações finais}

Nosso objetivo com este breve estudo foi apontar algumas direções bastante férteis de estudo da indumentária e da moda no Brasil, estabelecendo diálogo com o ensino de Artes Visuais no Ensino Médio e nos anos finais do Ensino Fundamental.

Pudemos observar que os relatos (textuais e iconográficos) dos viajantes estrangeiros são fontes de extrema importância para o estudo da indumentária brasileira. Porém, esses discursos precisam ser analisados cuidadosamente, localizando seus autores em seus devidos lugares de fala. Por vezes, os próprios viajantes divergem de opinião ou se colocam de maneira claramente normativa, reafirmando o discurso de conterrâneos que estiveram no Brasil anteriormente. Discursos esses que insistem em desqualificar os brasileiros do período colonial e do início do império.

Por fim, destacamos a iconografia produzida pelos artistas viajantes, sobretudo durante o século XIX, como importante fonte de estudo da sociedade brasileira, sendo a indumentária uma chave de leitura ainda pouco explorada pelos professores da disciplina de Artes Visuais. 


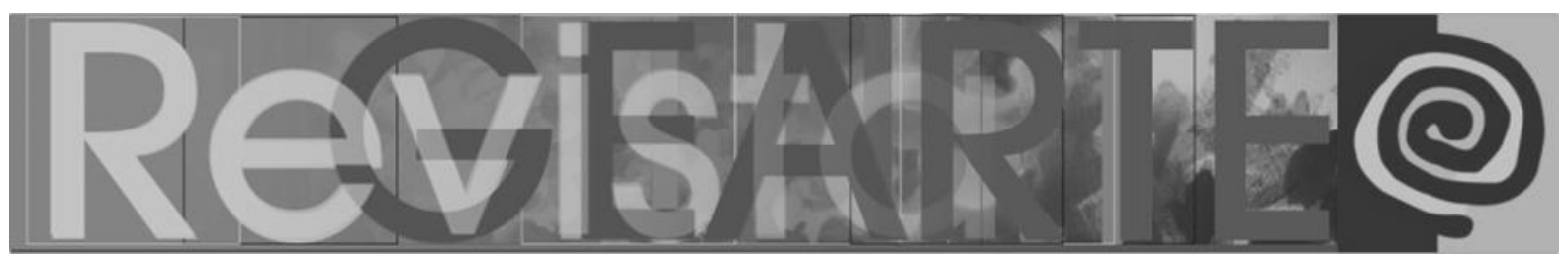

\section{Notas}

1 O objetivo de tal explanação é oferecer um panorama dos mais importantes estudiosos da moda e da indumentária. Estamos cientes da necessidade de problematizar e contextualizar os discursos destes autores e não tomá-los como absolutos.

2 A moda no século XIX foi o título da tese de doutorado de Gilda de Mello e Souza, defendida no departamento de Sociologia da USP, em 1950. Sabe-se, entretanto, que o trabalho não foi bem recebido pela academia naquele momento, tendo sido classificado como "coisas de mulher", e que só ganhou maior visibilidade 37 anos mais tarde, quando finalmente foi publicado (sob o título $O$ espírito das roupas) pela Companhia das Letras. Vale destacar que curiosamente essa edição chegou ao mercado em 1987, ano da abertura do primeiro curso de bacharelado em moda no país, oferecido pela Faculdade Santa Marcelina, em São Paulo.

3 Das sete autoras citadas, cinco estão vinculadas a programas de pós-graduação e atuam na pesquisa, orientação de pesquisas e no ensino da indumentária e da moda no campo das Artes. São elas: Maria Cristina Volpi (programa de pós-graduação em Artes Visuais - UFRJ), Maria Claudia Bonadio e Maria Lucia Bueno (programa de pós-graduação em Artes, Cultura e Linguagens - UFJF), Rita Andrade (programa de pós-graduação em Arte e Cultura Visual - UFG) e Mara Rúbia Sant'Anna (programa de pós-graduação em Artes Visuais - UDESC).

4 VIANA, Fausto. O traje de cena como documento. São Paulo: Estação das Letras e Cores, 2015.

5 "A influência francesa é marcante. As lojas do Rio de Janeiro estavam repletas de novidades que chegavam de Paris. Pela edição de 26 de junho de 1817 da Gazeta, o comerciante Carlos Durante avisava a seus clientes que havia se mudado da Rua do Ouvidor, número 28, para a Rua Direita, número 9, primeiro andar, onde oferecia os seguintes produtos: cheiros, água de Cologne, pomadas, diversas essências e vinagres para toucador e para mesa, luvas, suspensórios, sabão, leques de toda a sorte, escovas e pentes de todas as qualidades, sapatos, chinelas para homens e para senhoras, vestes de seda e de marroquim, todas de Paris, caixas de tabaco de toda espécie, necessário para homem, caixas de costura para senhoras, velas, azeite para luzes clarificado. Chapéus de palha e de castor para homens e para meninos; chapéus de palha para senhora, guarnecidos e não guarnecidos; chapéus de seda, penachos, fitas, filós bordados de ouro e prata, flores artificiais, casimiras, luvas, garças, véus, retrós, seda crua etc.; [...] bijuteria verdadeira e falsa, como colares, brincos, anéis e enfeites" (GOMES, 2007, p. 201).

6 "Foram os franceses do tempo do Sr. Pedro I, saiba-se, com as suas lojas de novidades, as suas costureiras, os seus cabeleireiros e umas instalações completamente novas para nós, feitas à moda de Paris, que criaram a elegância de certas casas de comércio da Rua do Ouvidor" (EDMUNDO, 2003, p. 43).

7 Sobre a invasão de produtos franceses no Rio de Janeiro, o arquivista real Luiz Joaquim dos Santos Marrocos relata em carta à irmã em Lisboa, em 1816: "Não posso explicar-te a abundância e a fartura das fazendas e quinquilharias francesas que têm inundado esta cidade. [...] Toda a gente se vê ataviada ao gosto francês, menos eu, que sou Portugal Velho, e ninguém me tira desta cisma" (GOMES, 2007, p. 191).

8 Edmundo (2000, p. 196) afirma que no tempo dos vice-reis todas as vestimentas eram "talhadas em panos de coloridos fulgurantes, que iam do verde-gaio ao vermelho-sangue-de-boi". Diante de cores tão vivas, é natural que o processo de acinzentamento não tenha sido assimilado tão rapidamente.

9 É preciso destacar que existe sempre um movimento de troca entre as partes. Assim, quando se trata de hábitos vestimentares, os países dominados importam muitos costumes, mas também são exportadores, ainda que em menor medida.

10 Salvador foi a capital do Brasil colônia por 214 anos, entre 1549 e 1763.

11 "Por longo tempo foi tão rígida a separação entre mulheres honestas e 'mulheres da vida' que, por essa separação, parece principalmente explicar-se o retardamento no uso de chapéus pelas senhoras do 


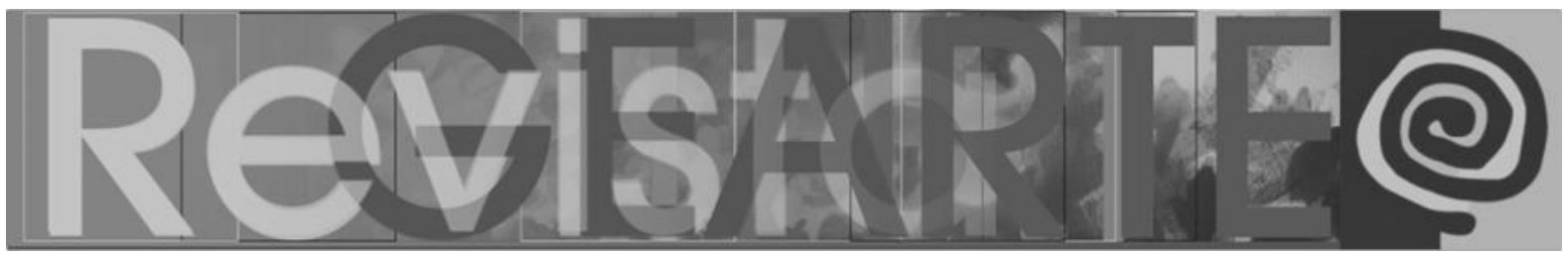

Brasil: chapéu era para 'mulher da vida'. A senhora verdadeiramente honesta só devia sair resguardada por mantilha" (FREYRE, 2004, p. 417).

\section{Referências}

BARBOSA, Ana Mae. Ensino da arte: memória e história. São Paulo: Perspectiva, 2014.

BARTHES, Roland. Sistema da moda. São Paulo: Wmf Martins Fontes, 2009.

BURKE, Peter. Testemunha ocular: história e imagem. Trad: Vera Maria Xavier dos Santos. Bauru: EDUSC, 2004.

DEBRET, Jean-Baptiste. Rio de Janeiro, cidade mestiça. São Paulo: Companhia das Letras, 2001. EDMUNDO, Luís. O Rio de Janeiro no tempo dos vice-reis: 1763-1808. Brasília, DF: Senado Federal, 2000.

EDMUNDO, Luís. O Rio de Janeiro do meu tempo. Brasília, DF: Senado Federal, 2003.

FAUSTO, Bóris. História do Brasil. São Paulo: EDUSP, 2010.

FRANÇA, Jean Marcel Carvalho. A construção do Brasil na literatura de viagem dos séculos XVI, XVII e XVIII: antologia de textos (1591-1808). São Paulo: Ed. Unesp, 2012.

FREYRE, Gilberto. Sobrados e mucambos: decadência do patriarcado e desenvolvimento do urbano. São Paulo: Global, 2004.

GOMES, Laurentino. 1808: como uma rainha louca, um príncipe medroso e uma corte corrupta enganaram Napoleão e mudaram a história de Portugal e do Brasil. São Paulo: Planeta do Brasil, 2007.

KNAUSS, Paulo. O desafio de fazer história com imagens: arte e cultura visual. Revista ArtCultura, Uberlândia, v. 8, n. 12, p. 97-115, 2006.

LUCCOCK, John. Notas sobre o Rio de Janeiro e partes meridionais do Brasil. Belo Horizonte: Itatiaia, 1975.

NACIF, Maria Cristina Volpi. Espaço, moda e vestuário - ou um esboço do lugar das roupas no campo da História da Arte. In: COLÓQUIO CBHA, 32., 2012, Campinas. Anais [...]. Campinas: CBHA, 2012. p. 1125-1137.

NASCIMENTO, João Affonso do. Três séculos de modas: 1616-1916. São Luís: Instituto Geia, 2014.

OLIVEIRA, Madson de. As múltiplas atividades de Sophia Jobim: feminista, jornalista, professora, figurinista, colecionadora. In: OLIVEIRA, Madson de; VOLPI, Maria Cristina (ed.). Arquivos da Escola de Belas Artes. Rio de Janeiro: Rio Books, 2016. p. 151-166.

RAINHO, Maria do Carmo Teixeira. A cidade e a moda: novas pretensões, novas distinções - Rio de Janeiro, século XIX. Brasília, DF: Universidade de Brasília, 2002.

RASPANTI, Márcia Pinna. Que deselegantes! Revista de História da Biblioteca Nacional, Rio de Janeiro, n. 89, p. 32-33, 2013.

RUGENDAS, Johann Moritz. Viagem pitoresca através do Brasil. São Paulo: Círculo do Livro, 1998.

SILVA, Maria Beatriz Nizza da. Vida privada e quotidiano no Brasil na época de D. Maria I e D. João VI. Lisboa: Editorial Estampa, 1993.

SILVA, Camila Borges da. A indumentária no museu: algumas considerações sobre memória e patrimônio. In: SILVA, Camila Borges da; MONTELEONE, Joana; DEBOM, Paulo (org.). A história na moda, a moda na história. São Paulo: Alameda, 2019. p. 303-330. 


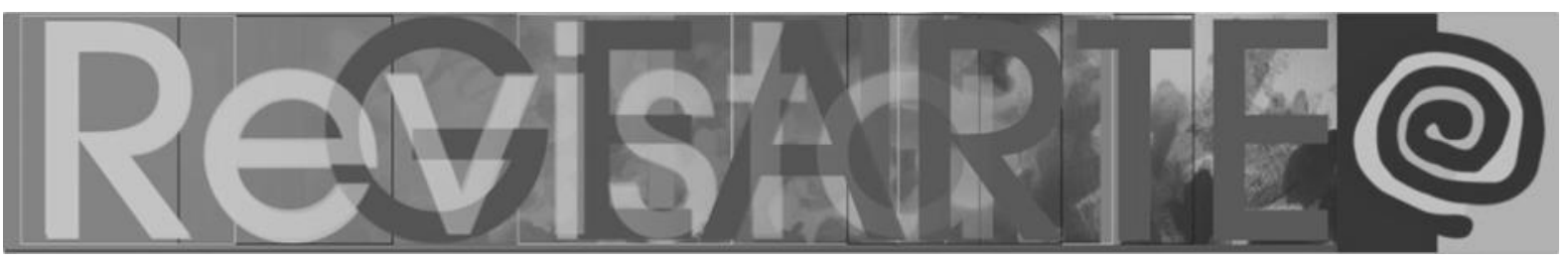

SOUZA, Gilda de Mello e. O espírito das roupas: a moda no século dezenove. São Paulo: Companhia das Letras, 1987.

VOLPI, Maria Cristina. Sofia Jobim e o ensino da indumentária histórica na E.N.B.A. Revista Maracanan, Rio de Janeiro, v. 12, n. 14, p. 300-309, 2016.

\section{Elton Luís Oliveira Edvik}

Mestrando na linha de pesquisa História e Crítica da Arte do programa de pós-graduação em Artes Visuais da Escola de Belas Artes da Universidade Federal do Rio de Janeiro. Bacharel em Artes Visuais com habilitação em Figurino e Indumentária pela Faculdade Senai CETIQT (2017) e discente no bacharelado em Letras - Língua e Literatura Francesa da Universidade Federal Fluminense. Foi professor substituto da Universidade Federal Rural do Rio de Janeiro no curso de Licenciatura em Belas Artes (2019) na área de Vestuário e Têxteis Atualmente é professor de Artes do segundo segmento do Ensino Fundamental.

ORCID: https://orcid.org/0000-0001-8013-5893

E-mail: eltonedvik@gmail.com

Currículo: http://lattes.cnpq.br/2792305704962271

Recebido em 12 de junho de 2020 Aceito em 19 de setembro de 2020 